\title{
Long-term 3D CT follow-up after endoscopic sagittal craniosynostosis repair
}

\author{
Amit Persad, MD, ${ }^{1}$ Keith Aronyk, MD, ${ }^{2}$ Wendy Beaudoin, $M N,{ }^{2}$ and Vivek Mehta, MD, $M{ }^{2}{ }^{2}$ \\ 'Division of Neurosurgery, Department of Surgery, University of Saskatchewan, Royal University Hospital, Saskatoon, \\ Saskatchewan; and 'Division of Neurosurgery, Department of Surgery, University of Alberta, Stollery Children's Hospital, \\ Edmonton, Alberta, Canada
}

OBJECTIVE Surgical treatment of sagittal synostosis involves various surgical modalities. Long-term follow-up issues include increased intracranial pressure, secondary sutural fusion, incomplete reossification, and suboptimal cosmetic appearance. The authors' objective in this study was to review their long-term endoscopic surgical results in children with sagittal synostosis using 3D CT.

METHODS The authors reviewed the long-term results of their first 38 patients who underwent endoscopic sagittal synostosis repair at age 16 weeks or younger. A standard vertex craniectomy with biparietal wedges was done in each case. After surgery, the children were fitted with a helmet, which they wore until 8 months of age. Patients were followed up for 5 years or longer, at which point a 3D CT scan was obtained. The authors examined data on the cranial index, area of bony defect, presence or absence of secondary sutural fusion, neosuture formation, and scalloping of the inner table of the skull.

RESULTS Thirty-two of 38 children met inclusion criteria. There was a small but significant recession of the cranial index after the completion of helmeting (from 0.772 after completion of helmeting to 0.755 at 5 years). Of 32 children, 14 had a bony defect area $>4 \mathrm{~cm}^{2}$. Three children had secondary sutural fusion (two unilateral coronal, one bicoronal). Ten of 32 patients had partial neosuture formation.

CONCLUSIONS The authors report their experience with 32 of their first 38 children who underwent endoscopic sagittal synostosis repair at 16 weeks of age or younger. With a minimum duration of 5 years, this is the longest clinicoradiological follow-up utilizing 3D CT to date in children with sagittal synostosis treated with endoscopic surgery. The authors report detailed measurements of bony loss, adjacent sutural fusion, and neosuture formation.

https://thejns.org/doi/abs/10.3171/2019.10.PEDS19297

KEYWORDS craniosynostosis; sagittal synostosis; scaphocephaly; endoscopic; reossification; cranial index; craniofacial

$\mathrm{C}$ RANIOSYNOSTOSIS is the premature fusion of one or more cranial sutures. Sagittal synostosis is the most common form of craniosynostosis. There are many surgical approaches used to treat scaphocephaly. These are divided into open surgery and endoscopic surgery. Cosmetic outcomes are similar between endoscopic and open surgery. ${ }^{4,7,12,13,15,16,21,29,30,33,38,41}$ Modifications to the endoscopic technique, including barrel staves, spring-assisted devices, and cinching sutures, have been reported..$^{17,35,40}$ Endoscopic surgery is associated with less blood loss, lower transfusion rates, decreased hospital length of stay (LOS), and decreased complication rates, $, 5,11,18,41$ as well as lower costs ${ }^{1,39}$ and less stress on parents. ${ }^{20}$

The neurosurgical follow-up issues for children who have had craniosynostosis surgery include cosmetic outcome, incomplete reossification, adjacent sutural disease, and elevated intracranial pressure (ICP). Cosmetic outcome and cranial index have been well studied following craniosynostosis surgery. In the short term, endoscopic surgery leads to cosmetic improvement. However, there is a recession of the cranial index over time toward the scaphocephalic phenotype., ${ }^{2,13,28}$ There are few studies addressing long-term surgical outcomes.

\section{Methods}

Institutional research ethics board approval was obtained for this study. 
This study was a single-center consecutive series of our first 38 children with isolated nonsyndromic sagittal synostosis in whom an endoscopic technique was used. Only children treated at age 16 weeks of age or younger were included. All children had a minimum 5-year follow-up duration. At 5 years or later, children underwent 3D CT scanning to characterize bony defects and skull morphology. The risks of radiation were discussed with families prior to booking the $\mathrm{CT}$ scan. Children who did not have clinical follow-up and a completed 3D CT scan were excluded.

All children were primarily operated on by a single surgeon (V.M.). Patients were positioned prone with a slight degree of head extension. Two 4-cm incisions were made, an anterior incision just posterior to the anterior fontanelle and a posterior incision just anterior to the lambdoid/ sagittal junction. Following a vertex craniectomy $(2.5 \mathrm{~cm}$ wide) with the assistance of an endoscope, small bilateral wedge craniectomies were completed. These were $1.5 \mathrm{~cm}$ in width and $3.5 \mathrm{~cm}$ in length and positioned at the anterior and posterior margins of the vertex craniectomy.

Within 4 weeks of surgery, the patients were sent for custom cranial orthotic fitting and began wearing the helmet 23 hours per day. They were followed monthly during the helmeting process, which took place until the patients were 8 months of age.

Following the conclusion of helmet therapy, each patient was followed up in the clinic yearly and measurements of head circumference and cephalic index were taken. At the 5-year follow-up visit, a 3D CT scan was offered; as stated, the risks of radiation were discussed with families.

Cranial indices were compared using one-way ANOVA. Paired t-tests were used to compare differences at each time point. Cranial indices were measured preoperatively, immediately following helmet removal, at the 1-year follow-up visit, and at the 5-year follow-up visit. IMPAX software was used for analysis of 3D CT scans. Cranial index, area of bony loss, evidence of neosuture formation, evidence of adjacent sutural fusion, and evidence of scalloping of the inner table of the skull were assessed.

Areas of bony loss were measured using the free-form region-of-interest tool. We defined incomplete ossification as any skull defect $>0.5 \mathrm{~cm}^{2}$. The two largest areas of bony loss $>0.5 \mathrm{~cm}^{2}$ were measured by two observers (V.M. and A.P.). The intraclass correlation coefficient (ICC) was computed with $95 \%$ confidence interval using SPSS software (version 24, IBM Corp.) to ensure interrater reliability of the measured data. Scalloping, neosuture formation, and adjacent sutural fusion were determined visually by both observers.

\section{Results}

We identified our first 38 patients who underwent endoscopic strip craniectomy at 16 weeks of age or younger. These patients had a minimum of 5 years of follow-up. Six patients were excluded for refusal to undergo 3D CT scanning ( 3 patients) or loss to follow-up ( 3 patients). Thirty-two patients were included (Fig. 1). The mean age at surgery was $12.5 \pm 2.6$ weeks. Twenty-five patients (78\%) were male and $7(22 \%)$ were female. The mean LOS was

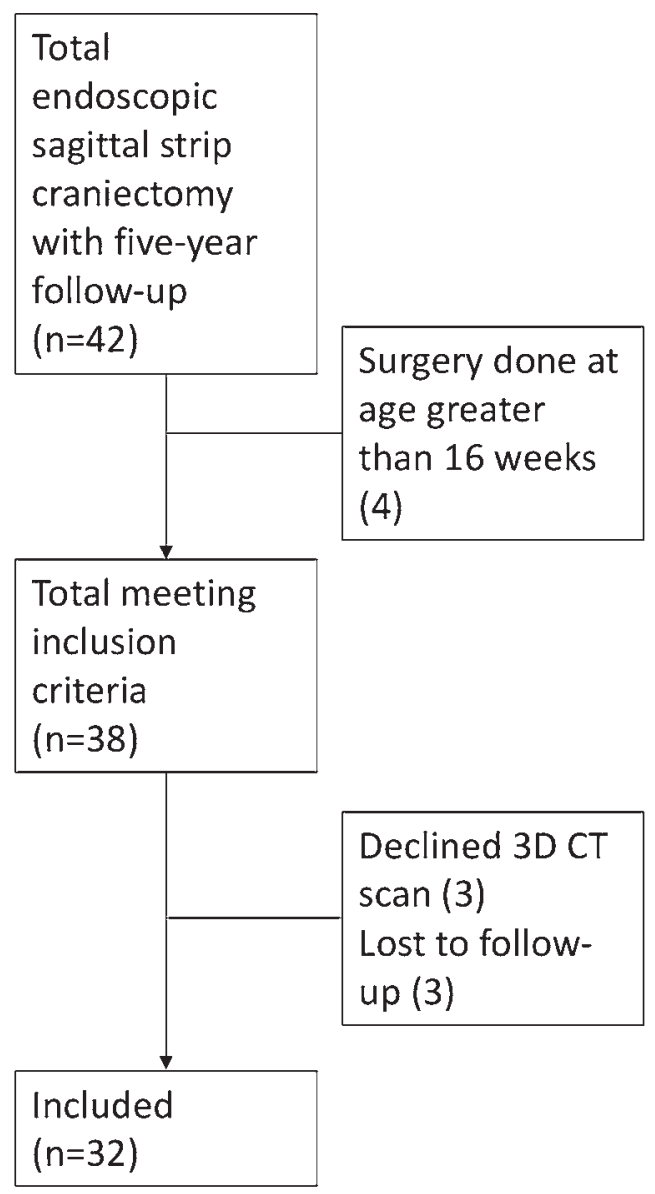

FIG. 1. CONSORT diagram detailing operative numbers and patient inclusion/exclusion. Thirty-eight of 42 candidates met age inclusion criteria. Of these, 32 completed 5-year clinical/3D CT follow-up and were included in the study.

$2.4 \pm 0.5$ days. The mean duration of helmeting was $4.7 \pm$ 1.6 months, with a mean of $1.4 \pm 0.5$ helmets used during that period. The mean age at the time of helmeting therapy completion was $8.5 \pm 1.8$ months, and the mean age at the time of 3D CT scan acquisition was $5.8 \pm 1.2$ years (Table 1). No children had dural tears, sinus injury, or deep postoperative infections.

The mean preoperative cranial index was 0.670 , which corrected to 0.772 at the time of completion of helmet therapy. The mean cranial index at the 1-year postoperative follow-up was 0.760 , and the mean cranial index measured on the 3D CT scan at the 5-year follow-up was 0.755 (Table 2). This was comparable to clinical measurement at the time of the 3D CT scan (0.756), with no statistical difference between measurement methods $(p=0.567)$. The difference between groups was significant $(p<0.001)$ on one-way ANOVA. Paired t-tests between groups revealed significant differences when comparing preoperative and posthelmeting data $(\mathrm{p}<0.001)$ and when comparing posthelmeting and 1 -year follow-up data for the cranial index $(p=0.003)$. The paired t-test showed no statistically significant difference between the cranial index at the 1-year follow-up visit and that at the time of the 3D CT 
TABLE 1. Demographic and follow-up data

\begin{tabular}{lc}
\hline Demographic \& Clinical Data & Value \\
\hline No. of patients & 32 \\
\hline Age at surgery, wks & $12.5 \pm 2.6(8.9-16)$ \\
\hline Male, no. $(\%)$ & $25(78)$ \\
\hline Female, no. $(\%)$ & $7(22)$ \\
\hline LOS, days & $2.4 \pm 0.5(2-3)$ \\
\hline Helmet duration, mos & $4.7 \pm 1.6(3-12)$ \\
\hline No. of helmets worn & $1.4 \pm 0.5(1-2)$ \\
\hline Age at end of helmeting, mos & $8.5 \pm 1.8(7.1-11.2)$ \\
\hline Age at 3D CT, yrs & $5.8 \pm 1.2(4.5-9)$ \\
\hline
\end{tabular}

Values are presented as the mean $\pm S D$ (range), unless otherwise stated.

scan $(\mathrm{p}=0.392)$ (Fig. 2). The ICC of cranial index measurements was 0.85 (95\% CI 0.82-0.88), which indicates good interrater reliability.

Twenty-seven of 32 children had some amount of bony defect as defined in Methods (Fig. 3). Fifteen of those 27 children had at least two areas of incomplete ossification. The range of bony defects was $0.6-13.5 \mathrm{~cm}^{2}$. Of the smaller measured defect, the mean area was $0.96 \mathrm{~cm}^{2}$. Of the larger measured defect, the mean area was $3.03 \mathrm{~cm}^{2}$. Fourteen $(44 \%)$ of 32 children had a total area of bony loss $>4$ $\mathrm{cm}^{2}$, and 9 (28\%) of 32 children had a single skull defect $>4 \mathrm{~cm}^{2}$ (Table 3). Two children had two separate areas of bony defect that were each $>4 \mathrm{~cm}^{2}$. Five children had no single defect $>4 \mathrm{~cm}^{2}$ but had a total area of the defect $>$ $4 \mathrm{~cm}^{2}$. The ICC values for bony area loss were $0.99(95 \%$ CI 0.98-1) and 0.97 (95\% CI 0.95-0.99) for the first and second areas, respectively, which indicates good interrater reliability. Among 14 children with $>4-\mathrm{cm}^{2}$ defect, consideration was given to surgical correction. Of these, only 3 patients underwent surgical repair of their cranial defect. This was done by split-thickness cranioplasty using autologous bone. There was a predilection of bony defects to occur along the vertex craniectomy rather than the wedge osteotomies.

Three children had adjacent sutural fusion (one left coronal, one right coronal, and one bicoronal) (Fig. 4). Ten children $(31 \%)$ had at least partial neosuture formation at the sagittal suture. Only 2 children had scalloping of the inner table of the skull (Table 4). None of the children exhibited clinical symptoms concerning for elevated ICP during follow-up. No children required a repeat operation due to poor cosmetic outcome, including those who had secondary sutural fusion.

\section{Discussion}

There have been few reports of long-term outcomes in endoscopic craniosynostosis surgery. ${ }^{2,6,13,28}$ Using clinical and imaging measures, Pickersgill et al ${ }^{28}$ found a small but significant regression of 0.017 in the cranial index and adjusted cranial index ${ }^{9}$ after helmeting. Isaac et al. ${ }^{13}$ also observed a greater regression in cranial index in an endoscopically treated group compared with an open surgically treated group. In the present study, we found a small regression, from a 1-year post-helmet therapy follow-up cranial index of 0.012 , which was the peak, to a long-term follow-up cranial index of 0.017 . This did not manifest clinically, and no patient needed a reoperation for a poor cosmetic outcome.

Secondary sutural fusion is a known sequela of craniosynostosis surgical repair. ${ }^{3}$ Three of 32 children had secondary sutural fusion seen on follow-up imaging. No child had a clinically significant cosmetic deformity or required surgery for repair of secondary sutural fusion. We did not test these children for genetic syndromes.

Elevated ICP occurs in $5 \%-10 \%$ of children as a late complication of craniosynostosis surgery. ${ }^{37}$ In our series, no children were symptomatic with elevated ICP during clinical follow-up. Two children did have scalloping of the inner table of the skull, which was noted on secondary imaging review in 2 of 3 children with adjacent sutural fusion. We determined scalloping to be present because there were indentations diffusely along the inner table of the skull. This was beyond the usual convolutional appearance seen in other children. The significance of this finding is unclear. In these 2 children, there were no symptoms or signs of elevated ICP. These children were not poor responders to surgery, with a cranial index improvement of 0.085 and 0.117 , respectively. In addition, they had no evidence of a head circumference growth that was static or below the 50th percentile. We will continue with clinical and ophthalmological follow-up of these children indefinitely. If any symptoms or signs of elevated ICP develop, then we will consider ICP monitoring.

Recently, partial or complete reformation of the sagittal

TABLE 2. Pre- and posttreatment age and cranial index values

\begin{tabular}{|c|c|c|c|c|c|c|c|}
\hline Time Point & Age & Cranial Index & $\begin{array}{c}\text { p Value } \\
\text { (paired t-test } \\
\text { vs preop) }\end{array}$ & $\begin{array}{l}\text { p Value (paired } \\
\text { t-test vs post- } \\
\text { helmeting) }\end{array}$ & $\begin{array}{c}\text { p Value } \\
\text { (paired t-test } \\
\text { vs 1-yr FU) }\end{array}$ & $\begin{array}{c}\text { p Value } \\
\text { (paired t-test } \\
\text { vs 3D CT) }\end{array}$ & $\begin{array}{c}\text { p Value } \\
\text { (ANOVA) }\end{array}$ \\
\hline Preop & $2.1 \pm 0.2 \mathrm{mos}$ & $0.670 \pm 0.006$ & & & & & \\
\hline Posthelmeting & $8.5 \pm 0.3 \mathrm{mos}$ & $0.772 \pm 0.007$ & $<0.001$ & & & & \\
\hline At 1-yr clinical FU & $1.6 \pm 0.1 \mathrm{yrs}$ & $0.760 \pm 0.006$ & $<0.001$ & 0.003 & & & \\
\hline At 5-yr clinical FU & $5.8 \pm 0.2$ yrs & $0.756 \pm 0.005$ & $<0.001$ & 0.003 & 0.401 & & \\
\hline At 3D CT & $5.8 \pm 0.2 \mathrm{yrs}$ & $0.755 \pm 0.007$ & $<0.001$ & 0.002 & 0.392 & 0.567 & $<0.001$ \\
\hline
\end{tabular}

$\mathrm{FU}=$ follow-up.

Mean values are presented \pm SEM. 


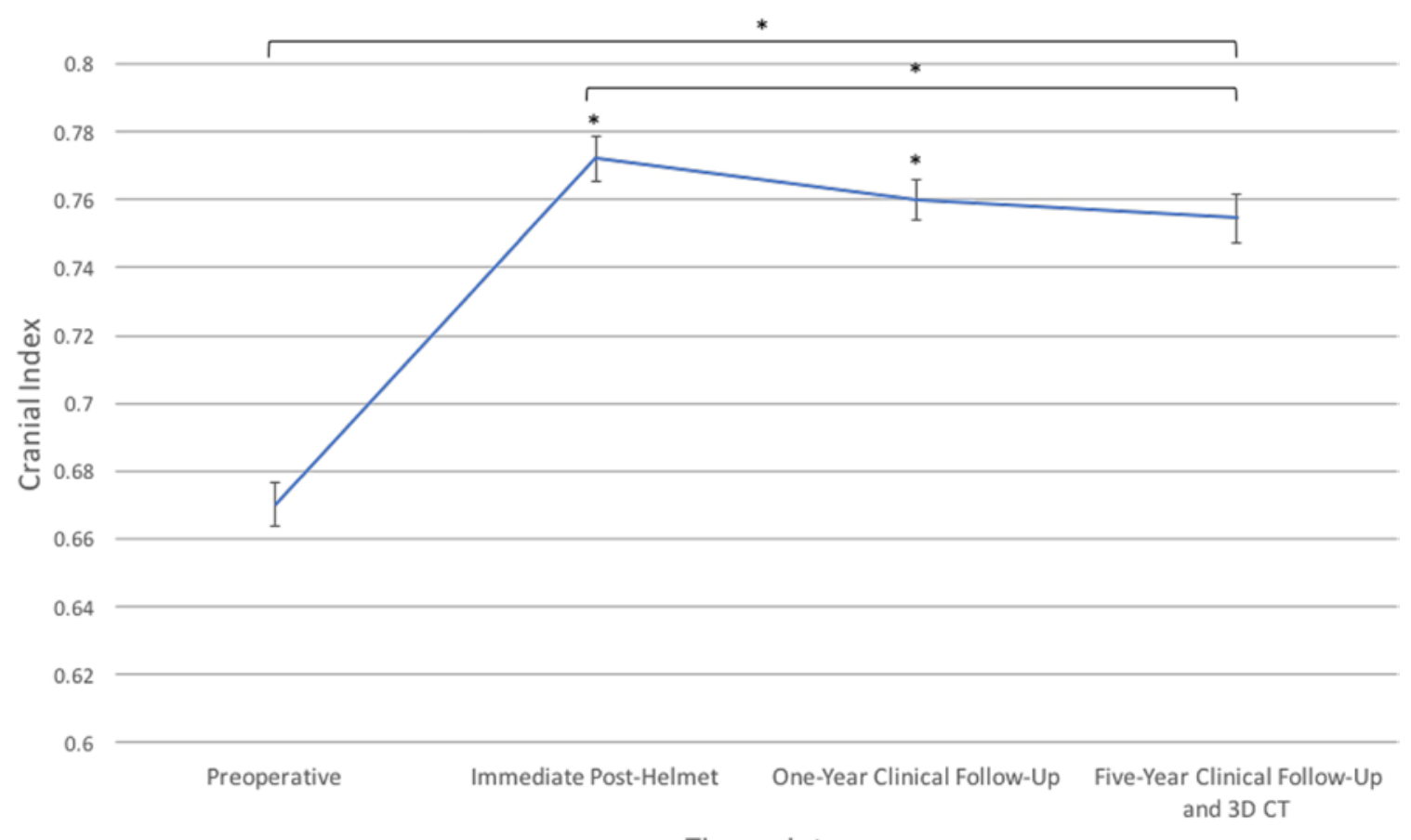

\section{Timepoint}

FIG. 2. Graph depicting cranial index at measured time points. Error bars represent standard error of the mean. One-way ANOVA showed a statistical change between time points $(p<0.001)$. Matched t-test showed no statistical difference between cranial indices at the 1-year follow-up and at the time of 3D CT ( $p=0.392)$, with the remainder significantly different. The ICC was 0.85 $(95 \% \mathrm{Cl} 0.82-0.88)$. Asterisks indicate statistical significance $(\mathrm{p}<0.05)$ for the time points being compared. Figure is available in color online only.

suture, or so-called neosuture formation, has been reported, ${ }^{32}$ with an incidence of approximately $25 \%$. The significance of the neosuture is uncertain. Ten patients (31.3\%) had at least partial neosuture formation demonstrated on 3D CT scans in our series.

Few studies have addressed incomplete ossification following craniosynostosis surgery. Noordzij and colleagues reviewed the literature and found rates of incomplete reossification ranging from $0.5 \%$ to $18.2 \%{ }^{26}$ They identified dural injury and infection as risk factors. Thenier-Villa et al. performed an analysis of 216 patients. In their series, $51.8 \%$ of patients who had undergone 3D CT had incom- plete reossification. Their reoperation rate due to bone defects was $5.56 \%$. Their findings were limited by the availability of the 3D CT scans (94 had recoverable scans, 101 had unrecoverable scans). They found larger postoperative defect and younger age to be risk factors. ${ }^{36}$ Age has inconsistently been reported as a risk factor for bone loss..$^{10,27,31,36}$

We observed 27 children $(84 \%)$ with at least a $0.5-\mathrm{cm}^{2}$ calvarial defect and $14(44 \%)$ with a combined area of loss $>4 \mathrm{~cm}^{2}$. Our prevalence of bony defects is higher than those previously reported. Three children $(9.4 \%)$ underwent surgery for a skull defect, which is higher than the rate reported by Thenier-Villa et al. ${ }^{36}$ The reoperation
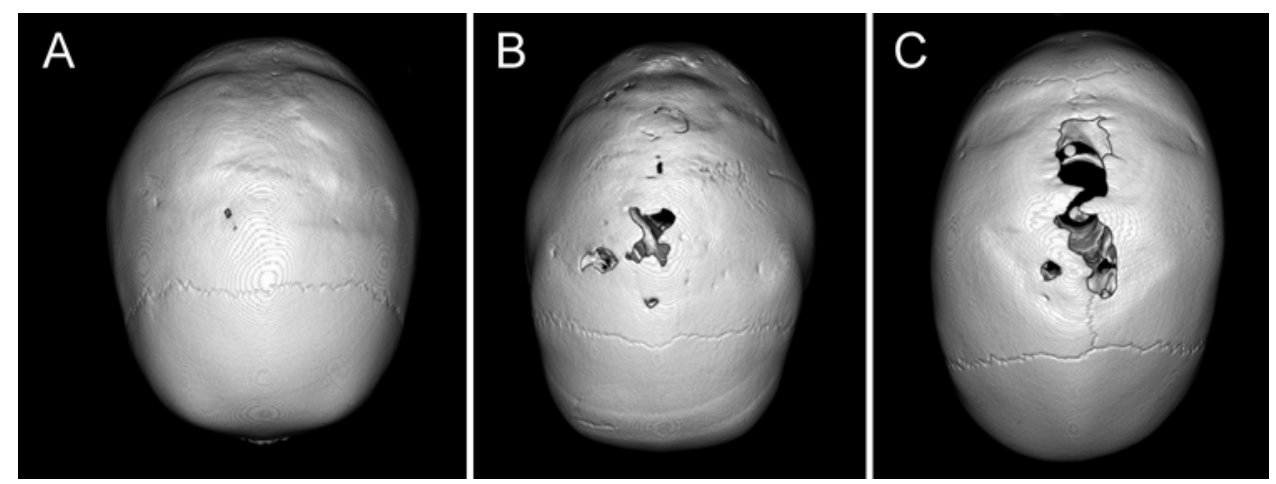

FIG. 3. Representative 3D CT scans showing an insignificant bony defect $\left(A ;<0.5 \mathrm{~cm}^{2}\right)$, a bony $\operatorname{defect}\left(\mathbf{B} ;>0.5 \mathrm{~cm}^{2}\right.$ but $\left.<4 \mathrm{~cm}^{2}\right)$, and a large bony defect $\left(\mathbf{C} ;>4 \mathrm{~cm}^{2}\right)$. 
TABLE 3. Cases of 3D CT-detected reossification failure

\begin{tabular}{lccc}
\hline $\begin{array}{c}\text { Bony } \\
\text { Defect }\end{array}$ & $\begin{array}{c}\text { No. of Children } \\
\text { w/ Defect }\end{array}$ & Mean Defect Area, $\mathrm{cm}^{2}$ & $\begin{array}{c}\text { No. of Children } \\
\text { w/ Defect Area } \\
>4 \mathrm{~cm}^{2}\end{array}$ \\
\hline Defect 1 & 27 & $3.03 \pm 0.51(0.75-8.83)$ & 9 \\
\hline Defect 2 & 15 & $0.96 \pm 0.29(0.55-6.77)$ & 2 \\
\hline Total & & $3.98 \pm 0.69(0.75-13.53)$ & 14 \\
\hline
\end{tabular}

The defect area is presented as the mean \pm SEM (range). Two children had two separate areas of bony defect, both $>4 \mathrm{~cm}^{2}$. Five children had no single defect $>4 \mathrm{~cm}^{2}$ but had a total area of defect $>4 \mathrm{~cm}^{2}$.

rates for endoscopic suturectomy and open cranial vault remodeling are around $3 \%$ and $1.6 \%-3.7 \%$, respectively, ${ }^{13}$ compared to our rates, which are higher. All patients were operated on at 16 weeks of age or younger. Our craniectomy size was relatively wide at $2.5 \mathrm{~cm}$. Some authors have tended toward a smaller craniectomy size. ${ }^{8,25}$ The areas of incomplete ossification were mainly in the area of the strip craniectomy and not at the site of the wedge osteotomies. This potentially implicates the wide vertex craniectomy as a source of incomplete reossification.

We used 3D CT scans for the assessment of ossification. Some authors have argued that a defect not detectable by finger palpation is not significant. ${ }^{24,27}$ The positive predictive value of finger palpation is $50 \%$ for defects > $4 \mathrm{~cm}^{2}$ and $71 \%$ for smaller defects. In a study of followup patterns for craniosynostosis surgery, 4 of 9 surveyed surgeons used CT scans as a follow-up tool. ${ }^{19}$ Each 3D CT scan of the head emits $0.57 \mathrm{mSv}$ of radiation. Modifications exist to reduce this radiation dose. ${ }^{24} \mathrm{~A}$ chest $\mathrm{CT}$ scan, which is considered to emit a safe radiation dose, has an exposure of $2 \mathrm{mSv}$, and the average yearly atmospheric exposure in Canada is $2-3 \mathrm{mSv} /$ year. Though the imaging did not affect the clinical course of the majority of children, it did guide follow-up for children with large defects or with scalloping of the inner table of the skull. We will continue to offer 3D CT scans for this reason, though we are uncertain of their clinical relevance.

Postoperative duration of helmet therapy is not standardized. In most published series, the period of helmeting lasts between 8 and 12 months. The authors of one report described a shorter period of 6 months. ${ }^{7}$ Two studies have reported on the nonoperative treatment of craniosynostosis with helmet only. ${ }^{23,34} \mathrm{~A}$ recent study tracked the cranial index during helmet therapy. After the maximum cranial index had been achieved, there was no benefit to further helmet therapy. ${ }^{14}$ The maximum cranial index occurred between 7 and 9 months postoperatively.

We used a shorter duration of helmet therapy with a goal of 8 months of age. This resulted in a mean of 4.7 months of helmet therapy, when patients were a mean age of 8.5 months. Our reasoning for this was twofold. First, in Alberta there is a significant population spread with limited access to helmet therapists. A shorter duration of helmet therapy would potentially decrease parents' financial and travel burdens. Second, according to head growth models, there is a decrease in the velocity of cranial expansion after 7-8 months. ${ }^{22}$ Currently we continue helmet therapy for our children until they are 8 months of age.
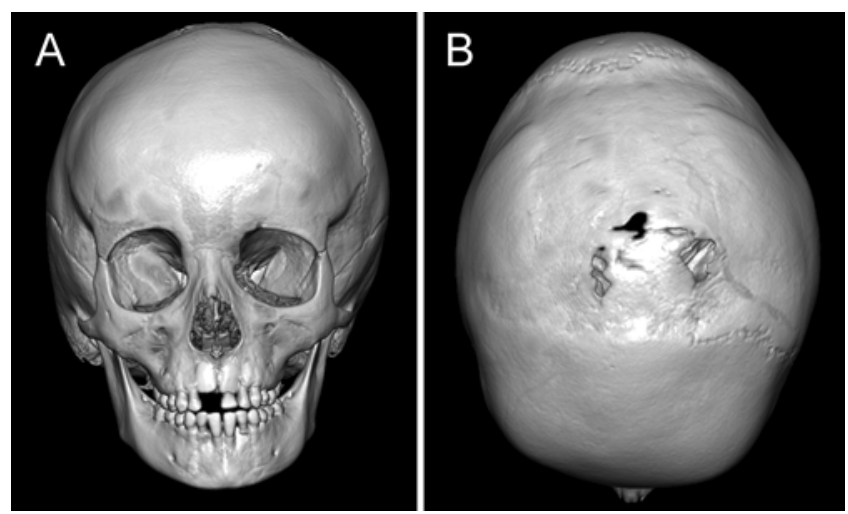

FIG. 4. A and B: Examples of secondary sutural fusion demonstrating a unilateral right coronal fusion.

There are multiple limitations of this study. This is a single-center study. Our sample size was limited to longterm follow-up of 32 of our first 38 endoscopic sagittal synostosis cases (early in the series) performed by the senior surgeon (V.M.) of a total of more than 100 cases to date. We were unable to include 6 patients due to refusal to undergo long-term 3D CT follow-up scanning (3 patients) or loss to follow-up (3 patients). We did not include data for the 3 cases in which 3D CT scanning was refused, but there were no clinical issues with the long-term followup for these 3 children. We used the cranial index as the measure for our study. More recently, the adjusted cranial index has been used to account for altered euryon location in children. ${ }^{9,28}$

The main purpose of this study was to review the longterm outcomes achieved with endoscopic sagittal synostosis repair. We have now considered narrowing our strip craniectomy and excluding the wedge osteotomies in our surgical technique. It is unclear if this will improve our rate of reossification failure. Another consideration is whether performing 3D CT scanning may impact individualized follow-up for these children. For children with good outcomes and no significant finding on 3D CT scans, further follow-up may be unnecessary. For children with secondary sutural fusion, scalloping of the inner table of the skull, or very large bony defects, continued follow-up may be necessary.

\section{Conclusions}

We report our long-term experience with 32 of our first 38 children who underwent endoscopic sagittal synostosis repair at the age of 16 weeks or younger. To our knowledge, this is the longest reported follow-up with 3D CT

TABLE 4. Other 3D CT-detected findings

\begin{tabular}{lc}
\hline \multicolumn{1}{c}{ Finding } & No. of Patients $(\%)$ \\
\hline Neosuture formation & $10(31.3)$ \\
\hline Adjacent sutural fusion & $3(9.4)$ \\
\hline Scalloping & $2(6.3)$ \\
\hline
\end{tabular}


to address cranial index, bone loss, adjacent sutural fusion, and neosuture formation. More research is needed to qualify these outcomes and to determine their relevance.

\section{Acknowledgments}

We would like to acknowledge C. Shinbine and L. Bliss from the pediatric head shape clinic for their clinical contributions and for their assistance in data recording. We would also like to acknowledge Dr. J. Souster, a pediatric neurosurgeon at the Stollery Children's Hospital. In addition, we would like to thank Drs. S. Walling and J. Kestle for their thoughtful comments on our manuscript.

\section{References}

1. Abbott MM, Rogers GF, Proctor MR, Busa K, Meara JG: Cost of treating sagittal synostosis in the first year of life. J Craniofac Surg 23:88-93, 2012

2. Agrawal D, Steinbok P, Cochrane DD: Long-term anthropometric outcomes following surgery for isolated sagittal craniosynostosis. J Neurosurg 105 (5 Suppl):357-360, 2006

3. Arnaud E, Capon-Degardin N, Michienzi J, Di Rocco F, Renier D: Scaphocephaly part II: Secondary coronal synostosis after scaphocephalic surgical correction. J Craniofac Surg 20 (Suppl 2):1843-1850, 2009

4. Bonfield CM, Lee PS, Adamo MA, Pollack IF: Surgical treatment of sagittal synostosis by extended strip craniectomy: cranial index, nasofrontal angle, reoperation rate, and a review of the literature. J Craniomaxillofac Surg 42:10951101,2014

5. Chan JW, Stewart CL, Stalder MW, St Hilaire H, McBride L, Moses MH: Endoscope-assisted versus open repair of craniosynostosis: a comparison of perioperative cost and risk. J Craniofac Surg 24:170-174, 2013

6. Chou PY, Hallac RR, Patel S, Cho MJ, Stewart N, Smartt JM, et al: Three-dimensional changes in head shape after extended sagittal strip craniectomy with wedge ostectomies and helmet therapy. J Neurosurg Pediatr 19:684-689, 2017

7. Cohen SR, Pryor L, Mittermiller PA, Meltzer HS, Levy ML, Broder KW, et al: Nonsyndromic craniosynostosis: current treatment options. Plast Surg Nurs 28:79-91, 2008

8. Dlouhy BJ, Nguyen DC, Patel KB, Hoben GM, Skolnick GB, Naidoo SD, et al: Endoscope-assisted management of sagittal synostosis: wide vertex suturectomy and barrel stave osteotomies versus narrow vertex suturectomy. J Neurosurg Pediatr 25:674-678, 2016

9. Dvoracek LA, Skolnick GB, Nguyen DC, Naidoo SD, Smyth MD, Woo AS, et al: Comparison of traditional versus normative cephalic index in patients with sagittal synostosis: measure of scaphocephaly and postoperative outcome. Plast Reconstr Surg 136:541-548, 2015

10. Greene AK, Mulliken JB, Proctor MR, Rogers GF: Primary grafting with autologous cranial particulate bone prevents osseous defects following fronto-orbital advancement. Plast Reconstr Surg 120:1603-1611, 2007

11. Han RH, Nguyen DC, Bruck BS, Skolnick GB, Yarbrough CK, Naidoo SD, et al: Characterization of complications associated with open and endoscopic craniosynostosis surgery at a single institution. J Neurosurg Pediatr 17:361-370, 2016

12. Honeycutt JH: Endoscopic-assisted craniosynostosis surgery. Semin Plast Surg 28:144-149, 2014

13. Isaac KV, Meara JG, Proctor MR: Analysis of clinical outcomes for treatment of sagittal craniosynostosis: a comparison of endoscopic suturectomy and cranial vault remodeling. J Neurosurg Pediatr 22:467-474, 2018

14. Iyer RR, Ye X, Jin Q, Lu Y, Liyanage L, Ahn ES: Optimal duration of postoperative helmet therapy following endo- scopic strip craniectomy for sagittal craniosynostosis. J Neurosurg Pediatr 22:610-615, 2018

15. Jimenez DF, Barone CM: Endoscopic craniectomy for early surgical correction of sagittal craniosynostosis. J Neurosurg 88:77-81, 1998

16. Jimenez DF, Barone CM, Cartwright CC, Baker L: Early management of craniosynostosis using endoscopic-assisted strip craniectomies and cranial orthotic molding therapy. Pediatrics 110:97-104, 2002

17. Jimenez DF, Barone CM, McGee ME, Cartwright CC, Baker CL: Endoscopy-assisted wide-vertex craniectomy, barrel stave osteotomies, and postoperative helmet molding therapy in the management of sagittal suture craniosynostosis. $\mathbf{J}$ Neurosurg 100 (5 Suppl Pediatrics):407-417, 2004

18. Johnson JO, Jimenez DF, Barone CM: Blood loss after endoscopic strip craniectomy for craniosynostosis. J Neurosurg Anesthesiol 12:60, 2000

19. Kestle JRW, Lee A, Anderson RCE, Gociman B, Patel KB, Smyth MD, et al: Variation in the management of isolated craniosynostosis: a survey of the Synostosis Research Group. J Neurosurg Pediatr 22:627-631, 2018

20. Kim D, Pryor LS, Broder K, Gosman A, Breithaupt AD, Meltzer HS, et al: Comparison of open versus minimally invasive craniosynostosis procedures from the perspective of the parent. J Craniofac Surg 19:128-131, 2008

21. Le MB, Patel K, Skolnick G, Naidoo S, Smyth M, Kane A, et al: Assessing long-term outcomes of open and endoscopic sagittal synostosis reconstruction using three-dimensional photography. J Craniofac Surg 25:573-576, 2014

22. Libby J, Marghoub A, Johnson D, Khonsari RH, Fagan MJ, Moazen M: Modelling human skull growth: a validated computational model. J R Soc Interface 14:20170202, 2017

23. Marupudi NI, Sood S, Rozzelle A, Ham SD: Effect of molding helmets on intracranial pressure and head shape in nonsurgically treated sagittal craniosynostosis patients. J Neurosurg Pediatr 18:207-212, 2016

24. Montoya JC, Eckel LJ, DeLone DR, Kotsenas AL, Diehn FE, Yu L, et al: Low-dose CT for craniosynostosis: preserving diagnostic benefit with substantial radiation dose reduction. AJNR Am J Neuroradiol 38:672-677, 2017

25. Nguyen DC, Farber SJ, Skolnick GB, Naidoo SD, Smyth MD, Kane AA, et al: One hundred consecutive endoscopic repairs of sagittal craniosynostosis: an evolution in care. J Neurosurg Pediatr 20:410-418, 2017

26. Noordzij N, Brouwer R, van der Horst C: Incomplete reossification after craniosynostosis surgery. J Craniofac Surg 27:e105-e108, 2016

27. Paige KT, Vega SJ, Kelly CP, Bartlett SP, Zakai E, Jawad AF, et al: Age-dependent closure of bony defects after frontal orbital advancement. Plast Reconstr Surg 118:977-984, 2006

28. Pickersgill NA, Skolnick GB, Naidoo SD, Smyth MD, Patel KB: Regression of cephalic index following endoscopic repair of sagittal synostosis. J Neurosurg Pediatr 23:54-60, 2018

29. Proctor MR: Endoscopic craniosynostosis repair. Transl Pediatr 3:247-258, 2014

30. Ridgway EB, Berry-Candelario J, Grondin RT, Rogers GF, Proctor MR: The management of sagittal synostosis using endoscopic suturectomy and postoperative helmet therapy. J Neurosurg Pediatr 7:620-626, 2011

31. Rocque BG, Agee BS, Thompson EM, Piedra M, Baird LC, Selden NR, et al: Complications following pediatric cranioplasty after decompressive craniectomy: a multicenter retrospective study. J Neurosurg Pediatr 22:225-232, 2018

32. Salehi A, Ott K, Skolnick GB, Nguyen DC, Naidoo SD, Kane AA, et al: Neosuture formation after endoscope-assisted craniosynostosis repair. J Neurosurg Pediatr 18:196-200, 2016

33. Shah MN, Kane AA, Petersen JD, Woo AS, Naidoo SD, Smyth MD: Endoscopically assisted versus open repair of 
sagittal craniosynostosis: the St. Louis Children's Hospital experience. J Neurosurg Pediatr 8:165-170, 2011

34. Sood S, Rozzelle A, Shaqiri B, Sood N, Ham SD: Effect of molding helmet on head shape in nonsurgically treated sagittal craniosynostosis. J Neurosurg Pediatr 7:627-632, 2011

35. Swanson JW, Haas JA, Mitchell BT, Storm PB, Bartlett SP, Heuer GG, et al: The effects of molding helmet therapy on spring-mediated cranial vault remodeling for sagittal craniosynostosis. J Craniofac Surg 27:1398-1403, 2016

36. Thenier-Villa JL, Sanromán-Álvarez P, Miranda-Lloret P, Plaza Ramírez ME: Incomplete reossification after craniosynostosis surgery-incidence and analysis of risk factors: a clinical-radiological assessment study. J Neurosurg Pediatr 22:120-127, 2018

37. Thomas GP, Johnson D, Byren JC, Judge AD, Jayamohan J, Magdum SA, et al: The incidence of raised intracranial pressure in nonsyndromic sagittal craniosynostosis following primary surgery. J Neurosurg Pediatr 15:350-360, 2015

38. Thompson DR, Zurakowski D, Haberkern CM, Stricker PA, Meier PM, Bannister C, et al: Endoscopic versus open repair for craniosynostosis in infants using propensity score matching to compare outcomes: a multicenter study from the Pediatric Craniofacial Collaborative Group. Anesth Analg 126:968-975, 2018

39. Vogel TW, Woo AS, Kane AA, Patel KB, Naidoo SD, Smyth MD: A comparison of costs associated with endoscope-assisted craniectomy versus open cranial vault repair for infants with sagittal synostosis. J Neurosurg Pediatr 13:324-331, 2014

40. Wood BC, Ahn ES, Wang JY, Oh AK, Keating RF, Rogers GF, et al: Less is more: does the addition of barrel staves improve results in endoscopic strip craniectomy for sagittal craniosynostosis? J Neurosurg Pediatr 20:86-90, 2017
41. Yan H, Abel TJ, Alotaibi NM, Anderson M, Niazi TN, Weil AG, et al: A systematic review and meta-analysis of endoscopic versus open treatment of craniosynostosis. Part 1: the sagittal suture. J Neurosurg Pediatr 22:352-360, 2018

\section{Disclosures}

The authors report no conflict of interest concerning the materials or methods used in this study or the findings specified in this paper.

\section{Author Contributions}

Conception and design: Mehta. Acquisition of data: Persad, Aronyk, Beaudoin. Analysis and interpretation of data: Mehta, Persad. Drafting the article: Persad. Critically revising the article: Mehta, Persad. Reviewed submitted version of manuscript: Mehta, Persad. Statistical analysis: Persad. Administrative/technical/ material support: Mehta, Aronyk, Beaudoin. Study supervision: Mehta.

\section{Supplemental Information}

\section{Previous Presentations}

Portions of this work appeared in poster form at the AANS Annual Scientific Meeting, New Orleans, Louisiana, April 28 to May 2, 2018.

\section{Correspondence}

Vivek Mehta: University of Alberta, Stollery Children's Hospital, Edmonton, AB, Canada. vivek.mehta@albertahealthservices.ca. 